\title{
Environmental Control of Moisture Content and Viability in Schlumbergera truncata (Cactaceae) Pollen
}

\author{
Thomas H. Boyle ${ }^{1}$ \\ Department of Plant and Soil Sciences, French Hall, University of Massachusetts, Amherst, MA 01003
}

AdDitional INDEX wORDs. breeding, fruit set, germplasm preservation, ornamental plants, seed

\begin{abstract}
Aвstract. The objective of this study was to determine the effects of temperature, relative humidity (RH), and storage duration on moisture content and viability of Schlumbergera truncata (Haworth) Moran (Thanksgiving cactus) pollen. Pollen viability was assayed by the fluorochromatic reaction (FCR) test, percentage fruit set, and numbers of viable seeds per fruit. Pollen moisture content was $\approx 38 \%$ at anthesis but decreased to $\approx 12 \%$ by 1 day after anthesis and remained low $(10 \%$ to $12 \%$ ) until flowers senesced. Pollen viability was $85 \%$ on the day of anthesis, remained at $\approx 80 \%$ from 1 to 3 days after anthesis, and decreased to $\approx 65 \%$ when flowers began to senesce. When pollen was stored for 4 days at $21^{\circ} \mathrm{C}$, moisture content decreased to $1 \%$ for pollen stored at $1 \% \mathrm{RH}$ but increased to $33 \%$ for pollen kept at $100 \%$ RH. Fruit and seed yields obtained with pollen stored for 4 days at $21{ }^{\circ} \mathrm{C}$ and $15 \%, 28 \%$, or $52 \% \mathrm{RH}$ did not differ significantly from those obtained with fresh pollen. Pollen stored for 4 days at $21^{\circ} \mathrm{C}$ and $1 \%, 68 \%$, or $90 \%$ RH produced fewer fruit and seeds than fresh pollen. Fruit and seed yields obtained with pollen stored 20 days at $21^{\circ} \mathrm{C}$ and $15 \%$ or $28 \%$ RH were similar to yields obtained with fresh pollen. Pollen with $\leq \mathbf{2 3 \%}$ moisture content that was stored at $\mathbf{- 1 8}{ }^{\circ} \mathrm{C}$ for $\geq \mathbf{2 4}$ hours retained its original viability $(\approx 85 \%)$ whereas pollen with a high $(32 \%$ to $34 \%)$ moisture content exhibited low $(\approx 22 \%)$ viability after storage at $-18^{\circ} \mathrm{C}$ for $\geq 24$ hours. Pollen stored for 140 days at 4 or $-18{ }^{\circ} \mathrm{C}$ and $13 \%$ to $51 \%$ RH yielded as many viable seeds per fruit as fresh pollen. Although $S$. truncata pollen is tricellular, it tolerates desiccation to a low (4\%) moisture content and can be stored at temperatures below $0{ }^{\circ} \mathrm{C}$.
\end{abstract}

Interspecific hybridization is commonly employed in breeding floricultural crops to broaden the genetic base (Ewart, 1981; Langton, 1985). Difficulties may arise when attempting to cross species with asynchronous flowering times. Breeders can either manipulate the environment (photoperiod and/or temperature) to synchronize the flowering times of different species or devise methods for collecting and storing pollen.

The genus Schlumbergera Lemaire contains six species of succulent perennials that are native to southeastern Brazil (Barthlott and Taylor, 1995). Schlumbergera truncata is grown as a flowering potted plant, but the other five Schlumbergera sp. are rare in cultivation and have not been exploited extensively for breeding commercial cultivars (McMillan and Horobin, 1995). A Schlumbergera breeding project has been underway at the University of Massachusetts and one of its principal aims is to broaden the germplasm base via interspecific hybridization. Schlumbergera sp. vary in their flowering times when plants are cultivated in greenhouses under natural photoperiods. For example, at lat. $40^{\circ}$ to $50^{\circ} \mathrm{N}$, the primary flowering period for Schlumbergera sp. is as follows: September and October for $S$. orssichiana Barthlott \& McMillan; November for S. kautskyi (Horobin \& McMillan) N.P. Taylor and S. truncata; February and March for S. russelliana (Hooker) Britton \& Rose; and March and April for S. opuntioides (Löfgren \& Dusén) D. Hunt and S. microsphaerica (Schumann) Hövel (Barthlott and Rauh, 1977;

Received for publication 18 Dec. 2000. Accepted for publication 15 May 2001. Massachusetts Agricultural Experiment Station publication no. 3286. This research was funded in part by the Cooperative State Research, Extension, Education Service, U.S. Department of Agriculture, Massachusetts Agricultural Experiment Station, under Project No. 746. I extend thanks to Robert L. Wick, Department of Microbiology, University of Massachusetts, for identifying fungi in stored pollen. The cost of publishing this paper was defrayed in part by the payment of page charges. Under postal regulations, this paper therefore must be hereby marked advertisement solely to indicate this fact.

'E-mail: tboyle@pssci.umass.edu.
McMillan and Horobin, 1995; T. Boyle, unpublished data). Time of flowering for $S$. truncata can be controlled by manipulating photoperiod and temperature (Boyle, 1997), but there have been no reports on environmental regulation of flowering for the other five Schlumbergera sp. Consequently, it would be desirable to store Schlumbergera pollen for crossing species with asynchronous flowering times.

Few studies have examined the storage requirements of cactus pollen. Pollen of Cereusflagelliformis Miller [currently Disocactus flagelliformis (L.) Barthlott] and Cereus grandiflorus [currently Selenicereus grandiflorus (L.) Britton \& Rose] remained viable for 13 and $17 \mathrm{~d}$ (respectively) when stored at 17.5 to $21{ }^{\circ} \mathrm{C}$ and $30 \%$ relative humidity (RH) (Pfundt, 1909). Cullmann et al. (1987) reported that cactus pollen would remain viable for 1 or 2 weeks if stored at 5 to $10^{\circ} \mathrm{C}$, but no data were presented. Pollen of Hylocereus undatus (Haworth) Britton \& Rose and H. polyrhizus (Weber) Britton \& Rose lost viability within $1 \mathrm{~d}$ when stored at room temperature, but pollen could be stored at -18 to $-196^{\circ} \mathrm{C}$ for at least 9 months if dehydrated to 5\% to $10 \%$ moisture content before storage (Metz et al., 2000).

The moisture status of pollen has a significant effect on its longevity (Towill, 1985). Two critical moisture levels exist for pollen. The upper level can be defined as the minimum moisture content at which freezable water is present, and pollen that reaches or exceeds the critical upper moisture level loses viability when exposed to freezing temperatures (Hanna and Towill, 1995). The lower level can be defined as the minimum moisture content at which viability is retained. Critical moisture levels vary among species and among genotypes within species (Hanna and Towill, 1995; Stanley and Linskens, 1974; Towill, 1985) and have not been defined for any Cactaceae taxa (Cullmann et al., 1987; Metz et al., 2000; Pfundt, 1909). The objective of this study was to determine the effects of temperature, $\mathrm{RH}$, and storage duration on the moisture content and viability of $S$. truncata pollen. 


\section{Materials and Methods}

Experiments were conducted from 1996 to 2000 on diploid ( $2 n$ $=22) S$. truncata plants grown in greenhouses at the Univ. of Massachusetts, Amherst (lat. 42 $22.5^{\prime} \mathrm{N}$ ). Plants were grown using standard greenhouse practices and flowering was induced by natural short-day photoperiods occurring from mid-September to April (Boyle, 1997).

Pollen viability. Pollen viability was assessed by the fluorochromatic reaction (FCR) test, percentage fruit set, and numbers of viable seeds per fruit. Fluorescein diacetate $\left(2 \mathrm{mg} \cdot \mathrm{mL}^{-1}\right.$ in acetone) was added dropwise to an aqueous solution of $0.8 \mathrm{M}$ sucrose until the solution became persistently cloudy (HeslopHarrison and Heslop-Harrison, 1970; Heslop-Harrison et al., 1984). Pollen samples were hydrated for $1 \mathrm{~h}$ at $100 \% \mathrm{RH}$ and 21 ${ }^{\circ} \mathrm{C}$ (Shivanna and Heslop-Harrison, 1981) then dispersed on a microscope slide in a drop of stain. Slides were incubated for $\approx 15$ min at $21^{\circ} \mathrm{C}$ and examined with a microscope (Standard 16, Carl Zeiss, Inc., Thornwood, N.Y.) equipped with a 100-W highpressure mercury lamp and a filter set for blue waveband excitation (exciter filter BP 450-490, dichromatic beam splitter FT 510, and barrier filter LP 520). Grains that were brightly fluorescing were scored as a positive FCR whereas grains that were weakly fluorescing or nonfluorescing were scored as a negative FCR. Intracellular accumulation of fluorescein (= positive FCR) indicates the presence of a semipermeable plasmalemma and esterase activity (Heslop-Harrison and Heslop-Harrison, 1970). Fruit and seed set data were collected in three experiments to ascertain if stored pollen could produce viable seed.

EFFECT OF FLOWER AGE ON MOISTURE CONTENT AND POLLEN VIABILITY (EXPT. 1). Flowers of 'Dark Marie' were examined several times daily for five consecutive days and a tag was applied to flowers on the day of anthesis. All flowers were harvested on the fifth day. Flowers were held above preweighed scintillation vials (with the anthers projecting into the vial) and pollen was dislodged from the anthers using a vortex mixer (model 232; Fisher Scientific Co., Pittsburgh, Pa.) set at the highest speed. Pollen was collected in the greenhouse under ambient temperature and $\mathrm{RH}$ and vials were capped immediately after collection. Each vial contained pollen from two flowers [ $\approx 20 \mathrm{mg}$ fresh weight $(\mathrm{FW})]$. After transfer to the laboratory $\left(21^{\circ} \mathrm{C}\right.$ and $\left.\approx 50 \% \mathrm{RH}\right)$, vials were uncapped and immediately weighed on an analytical balance. Vials were placed in a $85{ }^{\circ} \mathrm{C}$ forced-air oven for $24 \mathrm{~h}$ and reweighed. Moisture content (percentage FW) was determined for each sample. Pollen collection commenced at $1100 \mathrm{HR}$ and all samples were weighed and placed in the oven by $1200 \mathrm{HR}$. The experiment consisted of five time intervals $(0,1,2,3$, or $4 \mathrm{~d}$ after anthesis) with six replications (vials) per time interval.

Pollen collected $0,1,2,3$, or $4 \mathrm{~d}$ after anthesis was assayed for viability using the FCR test. Additional pollen samples collected at the same time as those described above were used for FCR tests. Pollen was hydrated and stained as described previously. Five samples were analyzed per time interval and $\geq 300$ grains were scored per sample. FCR tests were conducted on the day of pollen collection between 1330 and 1940 HR. Before hydration, pollen samples were held in capped scintillation vials on a laboratory bench $\left(21^{\circ} \mathrm{C}\right.$ and $\approx 15 \mu \mathrm{mol} \cdot \mathrm{s}^{-1} \cdot \mathrm{m}^{-2}$ irradiance from cool-white fluorescent lamps).

EFFECT OF RH ON POLLEN MOISTURE CONTENT (EXPT. 2). Pollen was collected from five different clones using the method described in Expt. 1. One sample was used to determine pollen moisture content and the remaining samples were stored for $4 \mathrm{~d}$ at $1 \%, 15 \%, 28 \%, 48 \%, 68 \%, 90 \%$, or $100 \%$ RH. RHs were controlled with anhydrous $\mathrm{CaSO}_{4}(1 \% \mathrm{RH})$, glycerol-water solutions $(15 \%$ to $90 \% \mathrm{RH})$, or deionized water $(100 \% \mathrm{RH})$. Glycerol-water solutions were prepared according to Forney and Brandl (1992). Actual RHs generated by the humidity control agents were measured with a Vaisala HMI38 data processor equipped with a HMP35E humidity and temperature probe (Vaisala Inc., Woburn, Mass.).

Pollen samples (50 to $140 \mathrm{mg}$ each) were placed in uncapped scintillation vials which in turn were placed inside screw top bottles $\left(138 \mathrm{~cm}^{3}\right.$ capacity) containing $25 \mathrm{~mL}$ of a humidity control agent. Each bottle contained one pollen sample. Pollen was placed in RH treatments within $1 \mathrm{~h}$ of collection. Preliminary experiments indicated that RHs remained constant when pollen samples were added to bottles containing $25 \mathrm{~mL}$ of a humidity control agent. Bottles were sealed with parafilm (Amer. Natl. Can, Greenwich, Conn.) and placed in a $21 \pm 1^{\circ} \mathrm{C}$ incubator. On day 4 , the moisture content of each sample was determined by the gravimetric method described previously.

EFFECT OF POLLEN STORAGE AT $21^{\circ} \mathrm{C}$ ON FRUIT AND SEED SET (EXPT. 3). A composite sample (14.3\% moisture content) was prepared using fresh pollen from four different clones. Pollen was stored for 4 or $12 \mathrm{~d}$ in a $21 \pm 1{ }^{\circ} \mathrm{C}$ incubator at RHs ranging from $1 \%$ to $90 \%$. RHs were controlled with anhydrous $\mathrm{CaSO}_{4}(1 \% \mathrm{RH})$ or glycerol-water solutions ( $15 \%$ to $90 \% \mathrm{RH}$ ). Viability of fresh and stored pollen samples was assayed by fruit and seed set. Stored pollen was rehydrated $\left(100 \% \mathrm{RH}\right.$ at $\left.21{ }^{\circ} \mathrm{C}\right)$ for $\approx 1 \mathrm{~h}$ before pollinations (Hanna and Towill, 1995). 'Eva' was used as the maternal clone for all crosses. Two control treatments were applied: flowers pollinated with fresh (day 0 ) pollen (to assess the normal amount of fruit and seed set) and nonpollinated flowers (to determine if flowers would set fruit without pollination). Pollen was applied with a fine artist's brush and each flower was pollinated once. Fifteen flowers were pollinated per treatment.

Fruit were harvested 7 months after pollination (Boyle et al., 1995) and seeds were cleaned by vacuum extraction (Boyle, 1994). Seeds were sown in 10-cm covered glass petri dishes containing one layer of blue blotter paper (Anchor Paper Co., Charlotte, N.C.) moistened with deionized water. Dishes were sealed with parafilm and placed in an incubator with $12 \mathrm{~h}$ days/ $12 \mathrm{~h}$ nights of $25 \pm 1 / 22 \pm 1{ }^{\circ} \mathrm{C}$ and a 12 -h photoperiod of $50 \pm 8$ $\mu \mathrm{mol} \cdot \mathrm{s}^{-1} \cdot \mathrm{m}^{-2}$ provided by cool-white fluorescent lamps.

The number of germinated seeds (those with protruding radicles) were recorded $30 \mathrm{~d}$ after sowing. Percentage fruit set $[$ (no. fruit set $/$ no. flowers pollinated $) \times 100]$ and number of viable seeds per fruit were calculated for each treatment. Percentage data were analyzed by the chi-square test and seed viability data were analyzed using analysis of variance procedures of SAS (SAS Inst. Inc., Cary, N.C.). Means for number of viable seeds per fruit were separated by the Waller-Duncan $k$ ratio $t$ test $(k=100)$.

EFFECT OF POLLEN STORAGE AT $21^{\circ} \mathrm{C}$ ON FRUIT AND SEED SET (EXPT. 4). A composite pollen sample (11.9\% moisture content) was collected from three different clones. Pollen was stored for $20 \mathrm{~d}$ at $21{ }^{\circ} \mathrm{C}$ and either $15 \%$ or $28 \%$ RH. RHs were controlled with glycerol-water solutions. The experimental protocol and methods used for data collection and statistical analysis were identical to those described in Expt. 3 except that pollen collected $20 \mathrm{~d}$ after the experiment commenced from flowers at anthesis (fresh pollen) was used as a control. Fifteen flowers were pollinated per treatment. 'Dark Marie' served as the maternal parent for all crosses.

EFFECT OF POLLEN MOISTURE CONTENT ON SURVIVAL AT $-18{ }^{\circ} \mathrm{C}$ 
(EXPT.5). Flowers were harvested on the day of anthesis from five different clones and pollen was extracted as described previously. After extraction, pollen $(\approx 800 \mathrm{mg})$ was taken immediately to the laboratory $\left(21 \pm 1.5{ }^{\circ} \mathrm{C}\right.$ and $\left.35 \% \pm 2 \% \mathrm{RH}\right)$ in a stoppered flask, mixed briefly in a vortex mixer, and spread in a thin layer in a 15$\mathrm{cm}$ glass petri dish. Samples were collected at 0, 0.25, 0.75, 1, 1.5, $2,3,4$, or $6 \mathrm{~h}$. Eleven samples were collected per time interval. Six samples $(\approx 12 \mathrm{mg}$ each) were placed in preweighed scintillation vials and dried for $24 \mathrm{~h}$ at $85^{\circ} \mathrm{C}$. Moisture content was determined as described previously. Five samples ( $\approx 3 \mathrm{mg}$ each) were placed in scintillation vials that were capped immediately afterwards and transferred to a $-18^{\circ} \mathrm{C}$ freezer for $\geq 24 \mathrm{~h}$. After storage at $-18^{\circ} \mathrm{C}$, pollen was warmed for $15 \mathrm{~min}$ at $21^{\circ} \mathrm{C}$, hydrated for $1 \mathrm{~h}\left(21^{\circ} \mathrm{C}\right.$ and $100 \% \mathrm{RH}$ ), and assayed for viability using the FCR test. Five pollen samples were analyzed per time interval and $\geq 300$ grains were scored per sample.

EFFECT OF POLLEN STORAGE AT 2 OR -18 ${ }^{\circ} \mathrm{C}$ ON FRUIT AND SEED SET (EXPT.6). Pollen ( $8.4 \%$ moisture content) was collected from three different clones and stored for $140 \mathrm{~d}$ in a $2 \pm 1.5^{\circ} \mathrm{C}$ refrigerator or $\mathrm{a}-18 \pm 2{ }^{\circ} \mathrm{C}$ freezer. RHs were controlled using anhydrous $\mathrm{CaSO}_{4}$ (1\% RH) and glycerol-water solutions (13\% to $51 \% \mathrm{RH})$. The experimental protocol and methods used for data collection and statistical analysis were identical to those described in Expt. 3, except that pollen collected $140 \mathrm{~d}$ after the experiment commenced from flowers at anthesis (fresh pollen) was used as a

Fig. 1. (A) Pollen moisture content and (B) percentage pollen grains eliciting a positive fluorochromatic reaction (FCR) in Schlumbergera truncata 'Dark Marie' flowers harvested from greenhouse-grown plants between the day of anthesis (day 0) and $4 \mathrm{~d}$ after anthesis (Expt. 1). Pollen was hydrated for $1 \mathrm{~h}$ at $21^{\circ} \mathrm{C}$ and $100 \%$ RH before staining. Vertical bars represent \pm 1 SD $(n=6$ and 5 for $\mathbf{A}$ and $\mathbf{B}$, respectively). control. Ten flowers were pollinated per treatment. 'Dark Marie' served as the maternal clone for all pollinations.

The clones used as maternal parents in Expts. 3, 4, and 6 were cross-compatible with all of the clones used as pollen donors ( $\mathrm{T}$. Boyle, unpublished data). Only clones with FCR scores $\geq 70 \%$ were used as pollen donors.

\section{Results and Discussion}

EXPERIMENT 1. During the experiment, greenhouse temperatures ranged from 16 to $27{ }^{\circ} \mathrm{C}$ and $\mathrm{RH}$ varied from 52 to $85 \%$. Pollen moisture content was $\approx 38 \%$ in newly opened flowers but decreased to $\approx 12 \%$ by $1 \mathrm{~d}$ after anthesis and remained low $(10 \%$ to $12 \%$ ) thereafter (Fig. 1A). Pollen viability was highest $(85 \%)$ on the day of anthesis, remained at $\approx 80 \%$ from 1 to $3 \mathrm{~d}$ after anthesis, and decreased to $\approx 65 \%$ at $4 \mathrm{~d}$ after anthesis (Fig. 1B).

Schlumbergera flowers remain open for several days (Scott et al., 1994), so it was pertinent to determine the moisture content and viability of pollen at different stages between anthesis and senescence. The 4-d period was selected for this experiment because 'Dark Marie' flowers last about $4.3 \mathrm{~d}$ at $20^{\circ} \mathrm{C}$ (Scott et al., 1994). Several of the flowers collected $4 \mathrm{~d}$ after anthesis had senesced, as indicated by turgor loss in the perianth and filaments. Despite this, FCR scores indicated that the majority of pollen grains remained viable up to $4 \mathrm{~d}$ after anthesis.

EXPERIMENT 2. Fresh pollen had a moisture content of $8.9 \% \pm$ $1.6 \%($ mean $\pm \mathrm{SD}, \mathrm{n}=5)$. Storage RH had a marked effect on pollen moisture content (Fig. 2). Pollen was dehydrated when stored at $\leq 48 \% \mathrm{RH}$ but became hydrated at $\geq 68 \% \mathrm{RH}$. Moisture content decreased to $1 \%$ for pollen stored at $1 \% \mathrm{RH}$ but increased to $33 \%$ for pollen maintained at $100 \% \mathrm{RH}$.

Connor and Towill (1993) examined hydration/dehydration characteristics of pollen from six species and found that the moisture content equilibrated within $24 \mathrm{~h}$ when the RH was $<97 \%$ whereas pollen stored over water required $>24 \mathrm{~h}$ to reach equilibrium. Given the fact that $S$. truncata pollen was kept in controlled RHs for $96 \mathrm{~h}$, it is reasonable to conclude that the pollen moisture contents reported herein are equilibrium values.

Pollen stored at $100 \% \mathrm{RH}$ exhibited greater variation in moisture content $(\mathrm{SD}=2.1)$ than pollen stored at lower $\mathrm{RHs}(\mathrm{SD}=$ 0.4 to 1.3 ). Variation in pollen moisture content at high RHs has been reported previously (Connor and Towill, 1993; Lanner,

Fig. 2. Effect of RH on equilibrium moisture content of Schlumbergera truncata pollen (Expt. 2). Pollen was stored at $21^{\circ} \mathrm{C}$ and constant RH (1 to 100\%) for 4 d. Vertical bars represent $\pm 1 \mathrm{SD}(\mathrm{n}=5)$. 